\title{
Validity of the physics affective characteristics scale for Flemish pharmacy and biology majors
}

\author{
Almer Gungorø* and Mieke De Cock \\ Department of Physics and Astronomy \& LESEC, KU Leuven, \\ Celestijnenlaan 200c, 3001 Leuven, Belgium
}

(Received 19 January 2021; accepted 24 March 2021; published 4 May 2021)

\begin{abstract}
The purpose of this study is to validate the physics affective characteristics scale (PACS) by investigating its psychometric properties. The PACS is a revised version of the affective characteristics scale (ACS), which was developed for Turkish students following introductory physics courses. The questionnaire includes 51 items in 11 subscales: situational interest in physics, personal interest in physics, relevance of physics to everyday life, relevance of physics to future career, relevance of physics to other courses, physics course anxiety, physics test anxiety, student motivation in physics, selfefficacy in physics, self-concept in physics, and physics achievement motivation. In this version, the relevance subscale-named as importance subscale in the previous version-was revised, and the aspiring extra activities related to physics subscale was removed. The PACS was administered to 240 nonphysics (biology and pharmacy) majors enrolled in an introductory physics course at a Flemish university. Confirmatory factor analysis was used to test the factor structure of the questionnaire. The results showed that the model fits well indicating that the revised questionnaire also has satisfactory psychometric properties, and supporting a multidimensional relevance construct. As expected, the indicators all showed significant positive factor loadings. The results of this study suggest that the Dutch version of the PACS is a useful instrument with sufficient reliability and validity to measure nonphysics majors' affective characteristics.
\end{abstract}

DOI: 10.1103/PhysRevPhysEducRes.17.010132

\section{INTRODUCTION}

Students' affective characteristics (motivation, attitudes, interest, relevance, expectations, self-efficacy, etc.) have been an interesting topic for physics education research (PER) for several decades. Questionnaires such as the Views about Science Survey (VASS) by Halloun [1], the Maryland Expectations about Science Survey (MPEX) by Redish et al. [2], and the Colorado Learning Attitudes about Science Survey (CLASS) by Adams et al. [3] were developed for different purposes and have been used for exploring various aspects of student perceptions about learning physics. Researchers' interest in the affective aspects of physics education continues [4,5].

VASS was developed [1] to explore students' perceptions about knowing or learning science and the relation of these perceptions to students' understanding of science. It

\footnotetext{
*almergungor@gmail.com
}

Published by the American Physical Society under the terms of the Creative Commons Attribution 4.0 International license. Further distribution of this work must maintain attribution to the author(s) and the published article's title, journal citation, and DOI. has two dimensions each with 3 subdimensions: Scientific dimension (structure, methodology, and validity) and cognitive dimension (learnability, critical thinking, and personal relevance). Similarly, MPEX was developed to survey student attitudes, beliefs, and assumptions about physics. It has 6 dimensions to investigate student beliefs about the nature of learning physics: independence, coherence, concepts, reality link, math link, and effort. Later, CLASS [3] was developed to explore student beliefs about physics and learning physics. The subscales of the CLASS are real-world connections, personal interest, sense making or effort, conceptual connections, applied conceptual understanding, problem solving general, problem solving confidence, and problem solving sophistication dimensions. Recent studies [5,6] provide support for a different structure for the CLASS than the originally proposed structure. This new structure has three dimensions: personal application and relation to real world, problem solving or learning, and effort or sense making.

All these questionnaires (VASS, MPEX, and CLASS) were developed to probe students' perceptions about learning physics (science) and include affective dimensions: personal interest in CLASS, personal relevance in VASS, reality link or real world connections in MPEX and CLASS, and problem-solving confidence in CLASS. 
The focus of these questionnaires was on students' beliefs about learning physics.

In addition, students' self-efficacy beliefs are more commonly studied in PER literature [4,7-15] than the other constructs in the affective domain. For example, the sources of self-efficacy in science courses-physics (SOSESC-P) survey developed by Fencl and Scheel in 2005 [9] has been used by many researchers, e.g., Refs. [12,13]. However, few researchers investigated other affective constructs (such as interest and anxiety) usually together with self-efficacy [16-19]. Dou et al. [16] examined students' interest and self-efficacy beliefs in introductory physics courses, whereas Britner [17] investigated high school students' self-concept, anxiety and achievement goal orientation, in addition to self-efficacy. Furthermore, Marshman and colleagues conducted a series of studies to investigate the gender differences in students' motivation [18] and physics identities [19], in which they adapted and validated surveys including interest and value associated with physics, in addition to self-efficacy and several identity constructs.

On the other hand, science education and educational psychology literature includes other widely studied affective constructs such as motivation, self-concept, anxiety, and achievement motivation that have been rarely studied in physics education literature. Therefore, the affective characteristics scale (ACS) [20] measuring interest, relevance, motivation, self-efficacy, self-concept, anxiety, and achievement motivation altogether might contribute to our understanding of students' perceptions of physics in a more comprehensive manner. These constructs are sometimes referred to as attitude or motivation in the literature. If they are referred to as attitude, they usually do not contain achievement motivation and confidence or expectancy beliefs such as self-concept and self-efficacy. However, we did not want to refer to them as motivation, since there are already achievement motivation and student motivation as separate constructs in the ACS. Therefore, we wanted to make the distinction between these constructs clear and preferred to use "affective characteristics" to refer to them collectively.

Furthermore, it is already known that nonphysics majors comprise a considerable fraction of students following introductory physics courses, and have different needs than physics majors [21]. Yet affective characteristics of these students have not been specifically investigated. Understanding the characteristics of these students might help physics education researchers and instructors in designing or implementing curricula more effectively for these groups. Therefore, we aimed to validate the Dutch version of the ACS for nonphysics (biology and pharmacy) majors enrolled in a compulsory introductory physics course at a Flemish university (Belgium) in order to be able to use it to understand these students' affective characteristics.

\section{SUMMARY OF DEVELOPMENT AND USE OF THE AFFECTIVE CHARACTERISTICS SCALE}

With the same purposes-since there were no comprehensive and compact questionnaire with strong psychometric properties to measure a collection of affective constructs in the PER literature-the ACS was developed by Abak in 2003 [22]. It was indeed developed to answer a need in the PER group of the researcher: to be used as a pretest and post-test in the experimental studies to control for affective variables, and subsequently it has been used for various studies to (i) predict achievement $[20,23,24]$, (ii) investigate gender differences [25], and (iii) measure affective characteristics before and after various interventions such as context-based approaches [26-28]. Some researchers [29] selected subscales of the ACS according to their needs. It was even adapted to chemistry [30].

The ACS includes items about students' (situational and personal) interest, relevance (labeled as importance in the Turkish version of the questionnaire), student motivation, self-efficacy, self-concept, (course and test) anxiety, and achievement motivation in physics, which will be collectively referred to as affective characteristics. The constructs that are included were determined by searching for the most commonly used constructs in the science education literature and their definitions are presented in Table I.

The questionnaire was developed in Turkish, but the items were collected from various questionnaires in English. The details of the questionnaire development and the selection of the affective characteristics with the theoretical backgrounds have been presented elsewhere [20,22]. Briefly, items from the literature were pooled, validated by expert viewsincluding verifications with Edwards' criteria [43] for attitude scales, student think-aloud interviews, exploratory factor analyses (EFA) [20,23,44], confirmatory factor analyses (CFA) [23], and reliability analyses [22-24,44]. The questionnaire was developed and validated with the sample of freshmen students following introductory physics courses in various faculties of three different universities. Later, it was used by another researcher with a sample of freshmen students following introductory physics courses at the education faculty of another institution [24]. Besides, it has also been used, e.g., Refs. [23,26,45] at the high school level [27,28,46-48].

Studies that investigated the psychometric properties of the ACS are summarized in Table II. The factor analyses of the ACS were generally consistent, with only minor differences, indicating that it was mostly generalizable to new populations. However, there was no evidence for its generalizability across cultures in another language. The internal consistency (Cronbach's alpha) coefficients ranged from 0.84 (self-concept) to 0.92 (test anxiety) in the original study with 890 freshmen students enrolled in physics courses at three different universities [20]. Consistently, they ranged from 0.76 (importance of physics) to 0.92 (test anxiety) in another study [24] with 353 
TABLE I. Definition of the constructs of the PACS.

\begin{tabular}{|c|c|}
\hline Construct & Definition \\
\hline $\begin{array}{l}\text { Relevance of } \\
\text { physics }\end{array}$ & $\begin{array}{l}\text { A "personally meaningful connection to the individual." [31]. The relevance in this study refers to students' } \\
\text { perceptions of usefulness, importance, and necessity of physics and physics courses for their everyday lives, } \\
\text { future careers, and other courses. }\end{array}$ \\
\hline Interest in physics & $\begin{array}{l}\text { A "psychological state of engaging or the predisposition to reengage with particular classes of objects, events, or } \\
\text { ideas over time" [32]. It is a content-specific concept [33]. In this study, it has two dimensions: Situational } \\
\text { interest-a "focused attention and affective reaction" that students acquire by participating in class [34], and } \\
\text { personal (individual) interest-"relatively enduring predisposition to engage" in the class [35]. }\end{array}$ \\
\hline Physics self-efficacy & $\begin{array}{l}\text { Perceptions of students' in their capabilities to organize and execute the sources of action required to manage } \\
\text { probable situations [36]. }\end{array}$ \\
\hline Physics self-concept & $\begin{array}{l}\text { A "person's perceptions regarding himself or herself" [37]. It is context-dependent. Academic self-concept } \\
\text { includes attitudes, feelings, and perceptions related to one's intellectual or academic skills, and represents a } \\
\text { mixture of self-beliefs and self-feelings regarding general academic functioning [38]. }\end{array}$ \\
\hline Physics anxiety & $\begin{array}{l}\text { A "feeling of nervousness or worry about something" [39]. In this study, it has two dimensions: physics test } \\
\text { anxiety and physics course anxiety. }\end{array}$ \\
\hline Student motivation & $\begin{array}{l}\text { The "contemporaneous, dynamic factors that influence such phenomena as the choice, initiation, direction, } \\
\text { magnitude, persistence, resumption, and quality of goal-directed (including cognitive) activity" [40]. }\end{array}$ \\
\hline $\begin{array}{c}\text { Achievement } \\
\text { motivation }\end{array}$ & $\begin{array}{l}\text { A "combination of psychological forces, which initiate, direct, and sustain behavior toward successful attainment } \\
\text { of some goal." [41]. It responds to the question: "To what extent does a student try to do as well as possible } \\
\text { when engaging in science?" [42]. }\end{array}$ \\
\hline
\end{tabular}

freshmen students enrolled in physics courses at a faculty of education in one university. The internal consistency coefficients of the subscales for high school samples $[23,44]$ were also good, with one exception: the achievement motivation subscale (0.66) in one study [44].

Even though ACS has strong psychometric properties for various Turkish student samples, no questionnaire (or test) is "valid for all purposes" - as validation of a questionnaire is limited to the specific use or interpretation for a certain population studied [49,50]. Therefore, researchers are responsible to check if the questionnaire has validation evidence appropriate to the intended use with that specific student group (e.g., with the specific age group, geographical location, language), and if insufficient validation evidence is found, the researcher might need to conduct a validation study [51]. In the Dutch version of the questionnaire, we decided to remove one subscaleaspiring extra activities related to physics-and revise the relevance subscale, which was previously named as the importance subscale in line with the current literature on relevance [31,52]. Specifically, the relevance scale was revised to have three subscales: everyday life, other or future courses, and future career in this version. The details of the changes are explained in Sec. III. We refer to this adapted version as the physics affective characteristics scale (PACS) and the items can be seen in Appendix A.

The purpose of this study was to examine the psychometric properties of the PACS for a Flemish nonphysics (biology and pharmacy) majors' dataset and to explore the interactions among the affective characteristics in physics. Therefore, the research questions were

1. What are the psychometric properties of the PACS for a Flemish nonphysics majors' dataset?
2. What are the interactions among affective characteristics measured by the PACS?

3. What are biology and pharmacy majors' physicsrelated affective characteristics?

\section{METHODS}

\section{A. Procedures}

In order to measure relevance in a more detailed way with three subscales, we revised the importance of physics and the course subscales, which consisted of 9 items [22]. In these new relevance subscales items 39, 40, 41 , and 47 were taken without any revisions, while the items $38,43,44,46,48$, and 50 were slightly revised from the importance subscale for daily life, other or further courses or future career relevance subscales. For example, "I think physics is important for the career I would like to follow" from the ACS was taken as item 47 without revision, and also revised for the other or future course relevance subscale as "I think this physics course is important for the other/further courses in my program" (item 43).

The items 45 (future or other courses) and 49 (career) were revised from a negative item "I will not use the info that we learn in physics class this semester again, so I don't need it." in the ACS, to read as follows in item 45 "I will need the info that we learn in this physics class in other or further courses." Items 42 (i.e., relevant to daily life) and 51 (to include students' everyday talk to read as "I don't understand why we learn physics to become a pharmacist/ biologist") were added to complement the definition of relevance. Later, expert views from one physics education professor, and a postdoc researcher in educational 


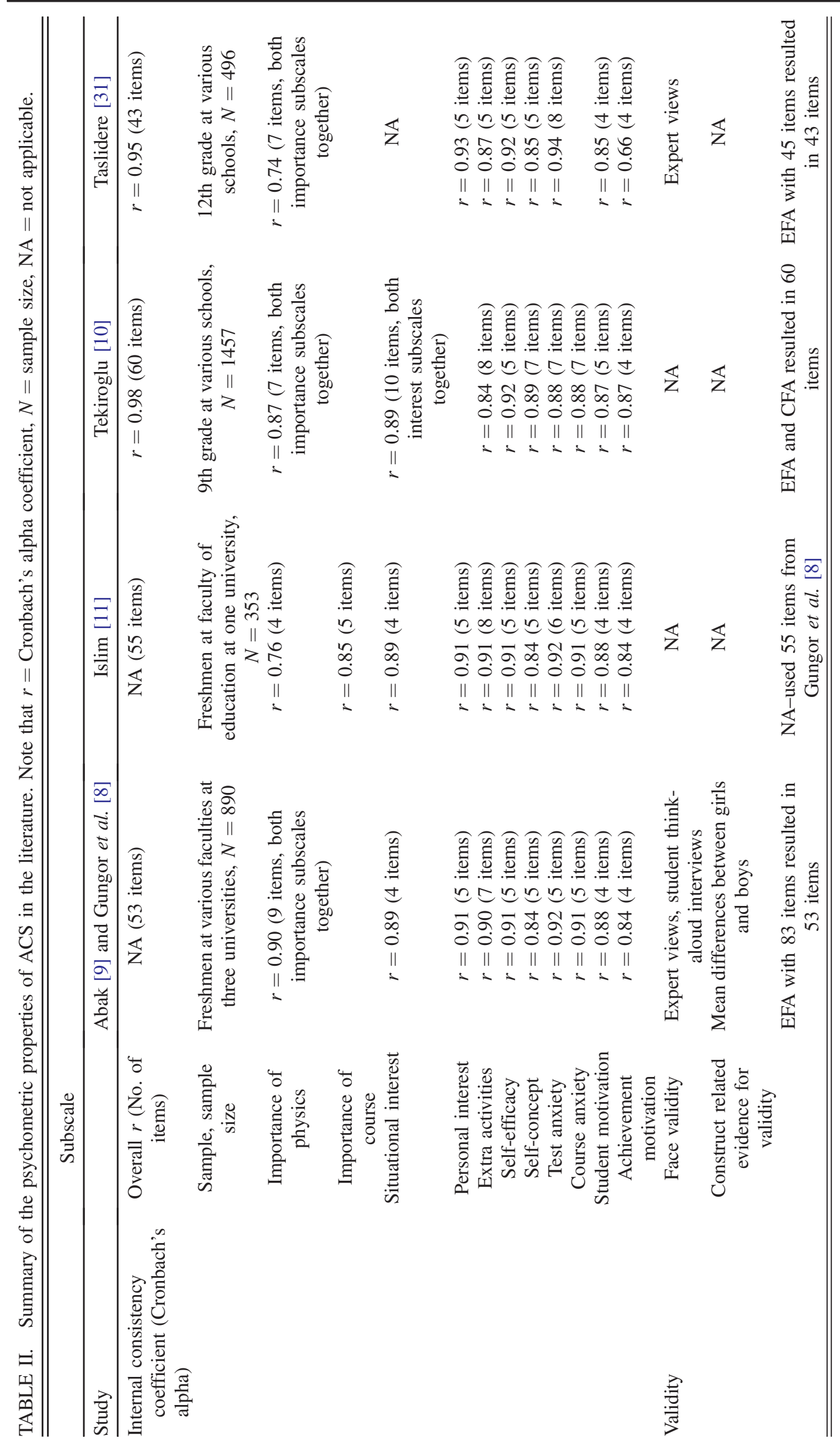


measurement and evaluation were asked, and minor revisions were done according to their feedback.

All items in the PACS have been translated to Dutch by first author, A.G., who translated the items in ACS from English to Turkish. Then three Dutch language experts (all native Dutch language teachers with 5-15 years of experience in teaching Dutch, with a bachelor's degree in Dutch linguistics, and one with a master's degree in Germanic languages), and also one physics education professor (M. D.C.), whose mother tongue is Dutch, verified the translational equivalence and clarity of the items in Dutch and English (original items from the item pool). Subsequently, in the spring semester of 20192020, in one recitation session of the course, 10 students in groups of two gave feedback on clarity, length, and appearance (font size, font style, and overall appearance) of the questionnaire. After each step, the questionnaire was revised iteratively according to the feedback.

Since we were planning to use the questionnaire in both semesters, in different courses, we wanted to make the distinction clear between the two courses. Thus, we have replaced "this course" in the original version with expressions such as "our physics course this semester" to make it clear that these items are on the first semester course.

The final version of the questionnaire was administered to the sample by A.G. in the fourth and fifth weeks of the fall semester of 2020-2021. After filling informed consent forms, students completed the questionnaires in approximately 15 min during lectures or recitations.

\section{B. Participants}

The sample of the study consisted of 172 (72\%) pharmacy and 68 (28\%) biology students. The majority of the students were female $(N=153,64 \%)$, while $35 \%$ $(N=85)$ were male, and 2 students did not respond to the question. The gender distribution of students in each group were approximately in accordance with the distributions of the student population in the same academic programs in Flanders [53].

The mean age of the students was 18.3 , while the minimum was 16 and the maximum was 33. In each group, more than $90 \%$ of the students were following the course for the first time, approximately $5 \%$ followed it for the second time, and around $2 \%$ for the third time.

\section{Context}

The introductory physics courses in both programs were similar: they both were 9 credit courses with the same professor and both courses included mechanics topics in the first weeks of the semester similar to many introductory physics courses for nonphysics majors. Due to COVID-19 regulations at the university, both course organizations were different from the usual organization of the introductory physics courses. The lectures were normally (preCOVID) $3 \mathrm{~h} /$ week, but were changed to one $3 \mathrm{~h}$ meeting every two weeks. The students received slides of the lectures with the professor's voice recordings that they had to study individually beforehand. For the lectures, they met at the campus once in two weeks to go over the most important points and examples with the professor in large groups (70-110 students). Their recitation sessions continued in class, but with less (approximately 20) students in each session and less interaction among the students than previous years. The recitations were $2 \mathrm{~h}$ /week.

\section{Preliminary analysis}

The items in the PACS were responded on a 5-point Likert scale that was labeled from 1 (strongly disagree) to 5 (strongly agree), 3 being the neutral point. Negatively worded items were reversely scored. Before any statistical analyses, data cleaning was conducted to find out if any student chose the same answer for all the items without reading - by comparing the positively stated items with the negatively stated items. Frequencies of each item were checked to control for mistakes in entering the data. As preliminary analyses, descriptive statistics were checked with SPSS version 27. Mean values, standard deviations, missing data, skewness, kurtosis, minimum and maximum values are presented in the Appendix B. Missing data analysis revealed that a maximum of $0.8 \%$ of the responses was missing, thus missing values have been replaced with the mean of each item. Twenty-three items had elevated means ( $>3.5$ on a 5-point scale), while the standard deviations were between 0.51 and 1.04. Skewness values ranged from -1.03 to 1.22 , whereas kurtosis values ranged from -1.08 to 2.04 .

\section{E. Data analysis}

The CFA tests theory-based hypothesis on the data. While conducting the CFA, it is recommended to have the following: (i) a sample size of at least 200 [54,55], and $N / t=3$, (where $t=$ number of items in the test), since acceptable models are rejected too frequently, if $N$ is small [55], (ii) at least 4 items per factor, and (iii) normally distributed data, i.e., items with skewness values lower than 1.5 [56]. All the recommendations were met in this study. The CFA was conducted in the R-lavaan package [57] to confirm the factor structure of the previous versions $[20,23,44]$ on our nonphysics majors' dataset. Although maximum likelihood (ML) is commonly used as the estimation method in CFA, unweighted least squares (ULS) provides more accurate factor loading estimates, and more precise standard errors for ordinal data $[56,58]$. Thus, we preferred a robust version of ULS estimation method-mean-adjusted test statistic (ULSM). The R code for the analysis is available as Supplemental Material [59].

\section{RESULTS}

To report the results of CFA, mentioning the following information about the model is recommended [60]: (1) fit of 
the model to the sample data, (2) strength of postulated relations between variables, (3) reliability of the parameter estimates, and (4) under appropriate circumstances, hypotheses tests regarding specific population parameters. Accordingly, in this study (1) goodness-of-fit indices were reported to check the fit of the model to the data, (2) standardized loadings and intercorrelations between the latent variables were presented to examine the strength of the relations between the variables, (3) estimates of the standard errors are given to check the reliability of the parameter estimates, and (4) two-tailed $t$-test statistics were also reported.

Since "each type of index provides different information about the model fit", the overall fit of the hypothesized model was evaluated using common goodness of fit (GOF) indices: chi-square with its degrees of freedom and $p$ value, root mean square error of approximation (RMSEA) and its 90\% confidence interval, comparative fit index (CFI), Tucker-Lewis index (TLI), and standardized root mean square residual (SRMR) [61]. The chi square is a measure of the overall model fit by comparing the sample and population covariance matrices [62]. The RMSEA is a measure of the degree of fit between the hypothesized model and the population covariance per degree of freedom [63]. The CFI and TLI are both relative fit indices, which compare the hypothesized model to the null model. The CFI is a normed fit index-ranges from 0 to 1 , whereas the TLI is a non-normed fit index - a value outside of the $0-1$ range is possible. The TLI and RMSEA control for the effect of model complexity [64]. The SRMR is an absolute fit index that measures the discrepancy between the sample and the hypothesized model covariance matrices [65].

To test model fit, chi square is compared with the expected value for given degrees of freedom [66]. For a good model fit, the recommended cutoff values for continuous data are [62]: 0.06 or below for the RMSEA, values below 0.08 for the SRMR, and values above 0.95 for the CFI and TLI. For ordinal data, same cutoff values are valid except for the SRMR-values below 0.07 are recommended [67]. However, the CFA conducted using ULSM as estimation method results in smaller RMSEA and larger CFI and TLI values than CFA conducted using ML [68].

To answer the first research question, the factor structure validated by the EFA by Gungor et al. [20] was tested and yielded close fit to data, $\chi^{2}(1169)=3085.612, p<0.001$, $\mathrm{CFI}=0.966$, TLI $=0.963$, RMSEA $=0.061$, SRMR $=$ 0.072. Both RMSEA and SRMR were slightly above the cutoff values in this model. The modification indices of this model proposed adding item 23 under the personal interest subscale. In other words, the first model recommended adding it to two subscales: course anxiety and personal interest. We checked the item wording and concluded that this modification was reasonable (see next section for the details). Thus, we decided to compare its loadings to these subscales by adding it to both of them at the same time. Its standardized loading to personal interest subscale was 0.55 , while course anxiety was 0.39 (decreased from 0.91 in the previous model). This second model yielded better fit than the first model, $\chi^{2}(1168)=2802.721$, $p<0.001, \mathrm{CFI}=0.971, \mathrm{TLI}=0.969, \mathrm{RMSEA}=0.056$, $\mathrm{SRMR}=0.069$.

Subsequently, we wanted to check a third model, in which item 23 loaded only to the personal interest subscale

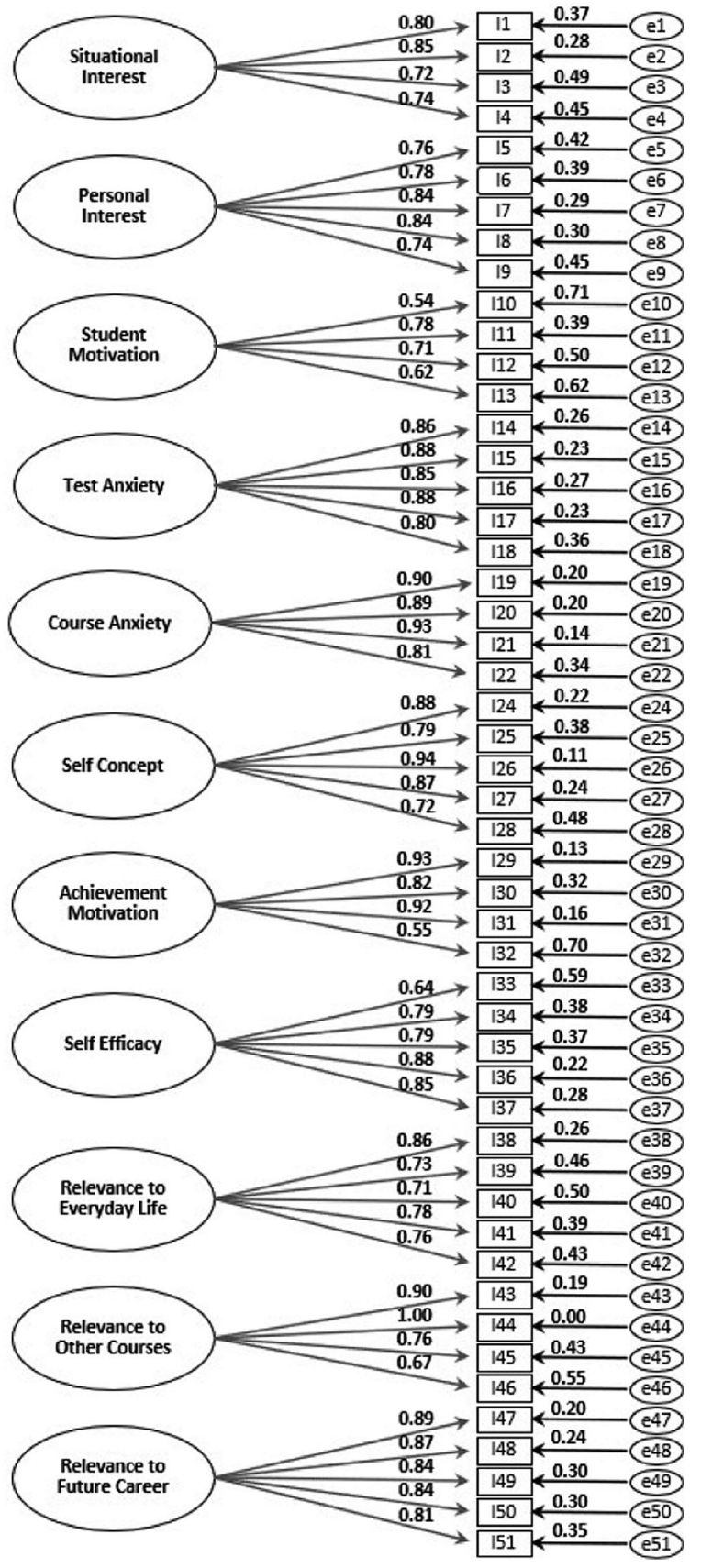

FIG. 1. Path diagrams for the CFA of the model with item 23 deleted. The numbers on the arrows represent the standardized loadings. All loadings were significant. Standardized errors are presented on the arrows at the right side of each item. 
TABLE III. Intercorrelations (corrected for measurement error) among the affective characteristics.

\begin{tabular}{|c|c|c|c|c|c|c|c|c|c|c|c|c|}
\hline & & (1) & (2) & (3) & (4) & (5) & (6) & (7) & (8) & (9) & (10) & (11) \\
\hline (1) & Situational interest & & & & & & & & & & & \\
\hline (2) & Personal interest & $0.74^{*}$ & $\cdots$ & & & & & & & & & \\
\hline (3) & Student motivation & $0.64^{*}$ & $0.80^{*}$ & $\cdots$ & & & & & & & & \\
\hline (4) & Test anxiety & $0.40^{*}$ & $0.49^{*}$ & $0.16^{*}$ & $\ldots$ & & & & & & & \\
\hline (5) & Course anxiety & $0.45^{*}$ & $0.41^{*}$ & $0.26^{*}$ & $0.65^{*}$ & $\ldots$ & & & & & & \\
\hline (6) & Self-concept & $0.39^{*}$ & $0.49^{*}$ & $0.32^{*}$ & $0.53^{*}$ & $0.33^{*}$ & $\cdots$ & & & & & \\
\hline (7) & Achievement motivation & $0.21^{*}$ & 0.12 & $0.29^{*}$ & -0.07 & $0.22^{*}$ & $0.19^{*}$ & $\cdots$ & & & & \\
\hline (8) & Self-efficacy & $0.49^{*}$ & $0.60^{*}$ & $0.36^{*}$ & $0.63^{*}$ & $0.43^{*}$ & $0.63^{*}$ & 0.07 & $\ldots$ & & & \\
\hline (9) & Relevance everyday life & $0.50^{*}$ & $0.39^{*}$ & $0.51^{*}$ & $0.12^{*}$ & $0.17^{*}$ & $0.27^{*}$ & $0.15^{*}$ & $0.30^{*}$ & $\ldots$ & & \\
\hline (10) & Relevance other courses & $0.32^{*}$ & $0.38^{*}$ & $0.44^{*}$ & 0.11 & $0.29^{*}$ & $0.16^{*}$ & $0.30^{*}$ & 0.05 & $0.41^{*}$ & $\cdots$ & \\
\hline \multirow[t]{5}{*}{ (11) } & Relevance future career & $0.40^{*}$ & $0.42^{*}$ & $0.53^{*}$ & 0.11 & $0.23^{*}$ & $0.21^{*}$ & $0.28^{*}$ & $0.20^{*}$ & $0.58^{*}$ & $0.63^{*}$ & $\cdots$ \\
\hline & Mean & 3.55 & 3.28 & 3.14 & 2.80 & 3.23 & 3.28 & 4.30 & 3.10 & 3.09 & 3.96 & 3.50 \\
\hline & Standard deviation & 0.53 & 0.62 & 0.56 & 0.82 & 0.68 & 0.57 & 0.45 & 0.58 & 0.64 & 0.56 & 0.75 \\
\hline & Cronbach's alpha coefficient & 0.79 & 0.85 & 0.70 & 0.91 & 0.90 & 0.87 & 0.82 & 0.84 & 0.84 & 0.85 & 0.90 \\
\hline & Composite reliability coefficient & 0.80 & 0.86 & 0.70 & 0.91 & 0.92 & 0.88 & 0.84 & 0.85 & 0.84 & 0.86 & 0.90 \\
\hline
\end{tabular}

${ }^{*}$ Correlation is significant at the 0.05 level.

since its loading to this subscale was higher than the course anxiety subscale. This model yielded a better fit than the first but worse fit than the second model, $\chi^{2}(1169)=$ 2926.178, $p<0.001, \mathrm{CFI}=0.969$, TLI $=0.966$, RMSEA $=$ 0.058 , SRMR $=0.070$. Eventually, we checked a fourth model by deleting item 23 from the questionnaire. This model resulted a better fit than the first and third models, but slightly worse fit than the second model, $\chi^{2}(1120)=$ 2714.921, $p<0.001, \mathrm{CFI}=0.970, \mathrm{TLI}=0.967, \mathrm{RMSEA}=$ 0.057, SRMR $=0.069$. Figure 1 presents the fourth model (item 23 deleted) with standardized factor loadings-variances explained for the factor using the items as predictorsand standardized errors. All factor loadings were significant with standardized values ranging from 0.54 (for item 10), to 0.99 (for item 44).

To provide additional information for the psychometric properties of the PACS, first Cronbach's alpha values were calculated for the overall questionnaire (0.94) and each subscale as internal reliability evidences (Table III). Second, composite reliability values [69] for each subscale were calculated by using the online composite reliability calculator [70]. Reporting composite reliability values based on factor loadings are recommended in CFA. As can be seen in Table III, there are only slight differences between Cronbach's alpha and composite reliability values. For the subscales, both range from 0.70 for the student motivation subscale to 0.91 for test anxiety. When item 23 was deleted the Cronbach's alpha value for course anxiety subscale increased from 0.88 to 0.90 , while the composite reliability increased from 0.88 to 0.92 .

In order to provide an answer for the second research question, the correlations among the affective characteristics are presented in Table III. All correlations among the affective characteristics were significant, except for the correlations of achievement motivation with personal interest, test anxiety, and self-efficacy; test anxiety with relevance of other courses and relevance of future career; and self-efficacy with relevance of other courses. The correlations among the factors ranged from 0.05 to 0.80 . Interestingly, personal interest was more closely related to student motivation (0.80) than situational interest (0.74). As expected, facets (test and course) of anxiety (0.65), expectancies (self-concept and self-efficacy) in the course (0.63), and relevance of future career to relevance of everyday life $(0.58)$ or other courses $(0.63)$ were closely related. However, the correlation between the relevance of everyday life and the relevance of other courses was relatively lower (0.41) but still statistically significant. On the other hand, some of the correlations between distinct factors were relatively higher. For example, self-efficacy was closely related to test anxiety (0.63) and personal interest (0.60).

Additionally, students' mean scores for each subscale and the standard deviations are presented in Table III. Students' scores for each subscale were calculated by taking the average responses across the items, explicitly scores of students for all the items in one subscale were added and then divided to the number of items in that subscale to compare the results with each other and interpret them easily. The mean scores range between 2.80 (for test anxiety) and 4.30 (for achievement motivation). Except for the mean score of the test anxiety subscale, all of the mean scores are above the middle point.

\section{DISCUSSION}

The previous factor structures of the Turkish version of the ACS is supported by the CFA of the dataset of the Dutch version of the PACS implying that each subscale of 
the PACS measures one aspect of students' physics-related affective characteristics. Therefore, with the evidence at hand we can conclude that the Dutch version of the PACS with 11 subscales is a useful instrument to measure nonphysics majors' affective characteristics. Specifically, the subscales represent a collection of affective constructs that can be reliably differentiated from each other both theoretically and empirically. The significant correlations especially within the facets of each construct also supports the theoretical basis of the PACS. The satisfactory psychometric properties of the questionnaire in this study and in the previous research $[22-24,44]$ indicate that it might be used similarly across various student populations.

The only issue in the questionnaire was with item 23. The best fitting model was the one with item 23 loaded to both course anxiety and personal interest subscales at the same time, but with a higher loading for personal interest subscale. When we investigated the underlying reason, we have seen that this item reads as "I dread having to do physics." and it was reverse coded before the analyses. The English antonyms of dread including both "being calm/ confident" and "look forward to" might explain this situation. Checking the Dutch version of the item, we saw that it can be interpreted more like "It makes me sigh, I do not like it, it takes energy" and the antonym of "I look forward to." Given that we define the affective constructs distinct but closely related to each other, we decided to conduct a CFA without this item. This model actually yielded a better fit than the two models with this item loading either of the subscales (course anxiety or personal interest) alone, but slightly worse fit than the best fitting model (loading to both at the same time). After removing this item from the course anxiety subscale, the internal reliability coefficients of this subscale slightly improved (e.g., the composite reliability coefficient changed from 0.88 to 0.92 ).

When the model is further investigated, it is seen that the affective characteristics measured by the PACS correlate significantly with each other with a few exceptions. First, facets of the construct interest (situational and personal), anxiety (test and course), expectancies (selfconcept and self- efficacy), and relevance (future career, the relevance of everyday life and other courses) were closely related to each other supporting the theoretical backgrounds of these constructs. These correlations were in accordance with the results of the previous studies $[20,23]$ : for the freshmen data the correlation coefficient between situational and personal interest was 0.64 , test and course anxiety was 0.61 , self-concept and selfefficacy was 0.54 [20], while the items in the situational and personal interest subscales loaded to the same factor in the EFA of the high school data [23].

Furthermore, revision of the relevance as a multidimensional construct is supported empirically by the results of this study. In the previous studies, items about the relevance of either physics courses in general or the current physics course-including items on further studies, real or everyday life, and future career-were grouped under the same factor $[20,23,44]$; while in this study, the three relevance subscales were distinct from each other as proposed. Still, they correlate significantly with each other, supporting that they are facets of the same construct.

Second, significant correlations between distinct factors were observed. Personal interest, situational interest, and student motivation were closely related to each other similar to the previous studies [20,23], while self-efficacy was more closely related to personal interest and test anxiety compared to the previous studies $[20,24]$. These relationships were expected considering these constructs are all subdimensions of the same construct: affect-which is also supported by the high overall internal reliability of the questionnaire and in accordance with the previous studies. Besides, self-efficacy might be influenced by culture [20], which might have resulted in the lower correlations in the previous studies. Some of the findings of this study were contradictory to the findings of the previous ones. We found-compared to the Turkish freshmen sample [20]-lower correlations of achievement motivation with the other subscales. However, in that study, achievement motivation was still a distinct factor in the measurement model indicating that it was not so closely related to other factors in the questionnaire [20]. On the other hand, physics self-efficacy in this study had an insignificant correlation with the relevance of physics to other courses in students' academic programs, which might be understandable, since these students were nonphysics majors. Unfortunately, comparison of this insignificant relation with the previous studies is not possible as the relevance subscale was revised in this study and there were no previous studies conducted with nonphysics majors.

In addition, students' mean scores reveal that they perceive physics relevant to their other courses (3.96), and to their future career to some degree (3.50), but not that relevant to their everyday lives (3.09). They are motivated to achieve (4.30), moderately anxious in courses (3.23), while slightly more anxious in exams (2.80) than in courses. Students are interested (3.28-3.55), confident (3.10-3.28), and motivated to acquire further knowledge/skills in physics courses (3.14) slightly above the medium level.

A misinterpreted item lowers a subscales' internal consistency, while a low reliability coefficient might indicate low validity. Contrarily, when the reliability coefficient is within the acceptable range, it is not plausible that all items in that subscale are misinterpreted similarly to form a new consistent subscale [71]. The results of this study suggest that the PACS has good reliability in terms of internal consistency. The student motivation subscale had the lowest Cronbach's alpha coefficient, which was still acceptably reliable $(0.70)$, whereas it ranged from 0.85 to 0.88 in the previous studies $[23,24,44]$. Indeed, except for 
Cronbach's alpha coefficient of self-concept (0.91 in this study-was higher than previous studies), all subscales had higher values in the previous studies. A possible explanation for the relatively lower values in this study might be that Cronbach's alpha coefficient depends on sample size, and all sample sizes were larger in the previous studies compared to the current study.

Our aim in this study was to develop a Dutch instrument that measures similar constructs to the Turkish version of ACS to investigate the affective characteristics of Flemish nonphysics majors. The affective constructs in the PACS are clearly defined theoretical constructs from the literature with the original items in English. Moreover, A.G. has translated all the items both to Turkish and to Dutch from English, which might contribute to the comparability of the versions in English, Turkish, and Dutch. The results of the previous studies support the comparability of the Turkish version to the theoretical framework from the literaturethe source of the original items in English. The results of this study provide sufficient evidence of validity and reliability to confidently conclude that the Flemish nonphysics majors interpret the items (with the exception of item 23) in the PACS as the Turkish population understood them in the previous research in agreement with the theoretical basis $[22-24,44]$.

Validity is "a matter of degree" [50], and validation of an instrument is limited to the specific use or interpretation for the population being studied $[49,50]$. Taken together, the validity evidence at hand gives us confidence to think that the Dutch version of the PACS has high validity for understanding the affective characteristics of our target group as distinct constructs-each with sufficient internal consistencies - as defined theoretically in the literature, similar to the Turkish version. Nevertheless, further studies with different and larger student groups might contribute to a better understanding of the psychometric properties of the Dutch version.

Instruments such as MPEX and CLASS exist already in the PER literature to investigate students' perceptions about the physics courses. Nevertheless, these instruments do not address the affective constructs (e.g., self-efficacy, selfconcept, anxiety, and achievement motivation) that have been investigated in other fields such as science education or educational psychology. Even though Nair and Sawtelle [51] proposed relevance as a multidimensional construct, instruments in PER literature have not included items to differentiate between relevance facets, yet. With all these added dimensions, the PACS adds another useful tool to the list of the instruments in the PER literature.

\section{FUTURE DIRECTIONS}

This study was conducted under unusual circumstances due to COVID-19, which might have an unknown effect on the affective constructs of this study. Therefore, crossvalidation analysis with similar student groups under usual circumstances and also with different student groups might contribute to an accurate understanding of the affective aspects of the physics classrooms, because-even with similar models as in this study-differences in the relationships among these constructs may converge for different cultures, gender groups, age groups, etc.

A better understanding of affective aspects of the physics classrooms might be a beginning step for further studies to develop interventions enhancing students' affective characteristics that are particularly important in science education, since ignoring the affective aspects of science education yielded the present situation that students in many countries think that science is not related to them [72].

\section{ACKNOWLEDGMENTS}

The project "DiFuSeEM" leading to this application has received funding from the European Union's Horizon 2020 research and innovation programme under the Marie Sklodowska-Curie Grant Agreement No. 843951. We would like to thank Professor Dr. Patrick Wagner and Dr. Veerle Vanhoof for their support in collecting data, and the anonymous reviewers for their constructive feedback.

\section{APPENDIX A: THE ITEMS IN THE PHYSICS AFFECTIVE CHARACTERISTICS SCALE (PACS)}

English versions of the items in the PACS are below.

ITEMS

1. Our physics class is fun in this semester.

2. This semester I find the physics course interesting.

3. I actually look forward to going to physics class this semester.

4. Our physics class this semester is dull.

5. Physics courses are boring.

6. I have good feelings toward physics courses.

7. Physics courses are enjoyable to me.

8. I enjoy studying physics at school (university).

(Table continued) 


\section{ITEMS}

9. I like physics courses.

10. I want to develop my physics skills.

11. I am interested in acquiring further knowledge of physics.

12. I want to take more physics than I have to.

13. I plan to take as much physics as I can during my education.

14. Thinking about an upcoming physics test makes me anxious.

15. Taking an exam in a physics course makes me anxious.

16. A physics test would scare me.

17. Studying for a physics test makes me anxious.

18. Physics tests make me nervous.

19. I feel nervous in physics class

20. Walking into a physics class makes me anxious.

21. Physics usually makes me feel uncomfortable and nervous.

22. Physics makes me feel uneasy and confused.

23. I dread having to do physics.

24. I am capable of obtaining good grades in this physics course.

25. I am proud of my ability in this physics course.

26. I feel good about my work in this physics course.

27. I am proud of my achievements in this physics course

28. I am feeling as good as the other people in this physics course.

29. I try hard to do well in this physics course.

30. I try to do my best in this physics course.

31. I try hard in this physics course, no matter how difficult the work.

32. When I fail in this physics course that make me try that much harder.

33. If I have enough time I can do even the hardest problems in physics.

34. I am sure that I can learn physics.

35. I think I can handle more difficult physics problems.

36. I know I can do well in physics courses.

37. I am sure I could do advanced work in physics.

38. I think this physics course is important for real life.

39. I think what we learn in this physics course makes life easier.

40. The stuff we learn in this physics class will not be used in real life.

41. I think what we learn in this physics course is useful in daily living.

42. What we learn in this course are relevant to daily life.

43. I think this physics course is important for the other-further courses in my program.

44. I think this physics course will be useful for other-further courses.

45. I will need the info that we learn in this physics class in other-further courses.

46. The stuff we learn in this physics class will not be used in my other-further courses.

47. I think this physics course is important for the career I would like to follow.

48. I think this physics course will be useful for my career.

49. I will need the info that we learn in this physics class in my career.

50. The stuff we learn in this physics class will not be used in my career.

51. I don't understand why we learn physics to become a pharmacist. ${ }^{*}$

"The "pharmacist" was replaced by "biologist" in the version of the questionnaire administered to the biology group.

\section{APPENDIX B: DESCRIPTIVE STATISTICS}

Descriptive statistics for each item of the PACS, were checked as preliminary analyses and are provided below.

\begin{tabular}{lcccccccc}
\hline ITEM No. & Valid N & Missing $(\%)$ & Mean & Std. deviation & Skewness & Kurtosis & Minimum & Maximum \\
\hline I1 & 240 & 0 & 3.58 & 0.69 & 0.00 & -0.22 & 2 & 5 \\
I2 & 240 & 0 & 3.73 & 0.62 & -0.16 & 0.01 & 2 & 5 \\
I3 & 239 & $1(0.4 \%)$ & 3.08 & 0.72 & 0.21 & 0.11 & 1 & 5 \\
I4 & 240 & 0 & 3.79 & 0.64 & -0.37 & 0.44 & 2 & 5 \\
I5 & 240 & 0 & 3.59 & 0.90 & -0.49 & -0.28 & 1 & 5 \\
\hline
\end{tabular}

(Table continued) 


\begin{tabular}{|c|c|c|c|c|c|c|c|c|}
\hline ITEM No. & Valid N & Missing (\%) & Mean & Std. deviation & Skewness & Kurtosis & Minimum & Maximum \\
\hline I6 & 239 & $1(0.4 \%)$ & 3.27 & 0.77 & -0.17 & 0.16 & 1 & 5 \\
\hline I7 & 239 & $1(0.4 \%)$ & 3.34 & 0.74 & -0.27 & -0.60 & 2 & 5 \\
\hline I8 & 239 & $1(0.4 \%)$ & 3.24 & 0.71 & -0.02 & 0.01 & 1 & 5 \\
\hline I9 & 238 & $2(0.8 \%)$ & 2.96 & 0.77 & 0.02 & -0.29 & 1 & 5 \\
\hline $\mathrm{I} 10$ & 240 & 0 & 3.98 & 0.60 & -0.10 & 0.15 & 2 & 5 \\
\hline I11 & 239 & $1(0.4 \%)$ & 3.79 & 0.78 & -0.45 & 0.28 & 1 & 5 \\
\hline $\mathrm{I} 12$ & 240 & 0 & 2.30 & 0.86 & 0.66 & 0.79 & 1 & 5 \\
\hline $\mathrm{I} 13$ & 240 & 0 & 2.50 & 0.84 & 0.22 & 0.27 & 1 & 5 \\
\hline $\mathrm{I} 14$ & 240 & 0 & 2.64 & 0.93 & 0.11 & -0.41 & 1 & 5 \\
\hline $\mathrm{I} 15$ & 240 & 0 & 2.78 & 0.91 & -0.11 & -0.66 & 1 & 5 \\
\hline I16 & 240 & 0 & 2.95 & 1.04 & -0.17 & -0.70 & 1 & 5 \\
\hline I17 & 240 & 0 & 3.04 & 1.00 & -0.08 & -0.63 & 1 & 5 \\
\hline I18 & 240 & 0 & 2.62 & 0.94 & 0.44 & -0.22 & 1 & 5 \\
\hline I19 & 239 & $1(0.4 \%)$ & 4.12 & 0.77 & -0.98 & 2.04 & 1 & 5 \\
\hline $\mathrm{I} 20$ & 240 & 0 & 4.39 & 0.68 & -1.08 & 2.04 & 1 & 5 \\
\hline $\mathrm{I} 21$ & 240 & 0 & 4.24 & 0.79 & -1.03 & 1.22 & 1 & 5 \\
\hline $\mathrm{I} 22$ & 240 & 0 & 4.05 & 0.86 & -0.78 & 0.52 & 1 & 5 \\
\hline $\mathrm{I} 23$ & 238 & $2(0.8 \%)$ & 3.77 & 0.83 & -0.55 & 0.36 & 1 & 5 \\
\hline $\mathrm{I} 24$ & 239 & $1(0.4 \%)$ & 3.31 & 0.64 & -0.10 & 0.29 & 1 & 5 \\
\hline $\mathrm{I} 25$ & 240 & 0 & 3.27 & 0.68 & -0.08 & 0.07 & 1 & 5 \\
\hline I26 & 240 & 0 & 3.31 & 0.66 & -0.27 & 0.52 & 1 & 5 \\
\hline $\mathrm{I} 27$ & 240 & 0 & 3.26 & 0.66 & -0.25 & 1.01 & 1 & 5 \\
\hline $\mathrm{I} 28$ & 240 & 0 & 3.27 & 0.81 & -0.39 & -0.17 & 1 & 5 \\
\hline I29 & 240 & 0 & 4.34 & 0.55 & -0.07 & -0.70 & 3 & 5 \\
\hline $\mathrm{I} 30$ & 240 & 0 & 4.42 & 0.51 & 0.13 & -1.53 & 3 & 5 \\
\hline $\mathrm{I} 31$ & 240 & 0 & 4.34 & 0.53 & 0.09 & -0.83 & 3 & 5 \\
\hline $\mathrm{I} 32$ & 240 & 0 & 4.23 & 0.61 & -0.50 & 1.13 & 2 & 5 \\
\hline $\mathrm{I} 33$ & 240 & 0 & 2.98 & 0.85 & 0.07 & 0.05 & 1 & 5 \\
\hline $\mathrm{I} 34$ & 240 & 0 & 3.70 & 0.64 & -0.54 & 0.46 & 2 & 5 \\
\hline $\mathrm{I} 35$ & 240 & 0 & 2.83 & 0.76 & 0.07 & -0.22 & 1 & 5. \\
\hline $\mathrm{I} 36$ & 239 & $1(0.4 \%)$ & 3.28 & 0.68 & -0.02 & 0.64 & 1 & 5 \\
\hline $\mathrm{I} 37$ & 240 & 0 & 2.78 & 0.73 & 0.17 & 0.34 & 1 & 5 \\
\hline $\mathrm{I} 38$ & 240 & 0 & 3.25 & 0.84 & -0.29 & -0.15 & 1 & 5 \\
\hline I39 & 240 & 0 & 2.80 & 0.78 & -0.01 & 0.18 & 1 & 5 \\
\hline $\mathrm{I} 40$ & 240 & 0 & 3.26 & 0.89 & -0.15 & -0.46 & 1 & 5 \\
\hline I41 & 240 & 0 & 3.08 & 0.80 & -0.09 & -0.35 & 1 & 5 \\
\hline I42 & 239 & $1(0.4 \%)$ & 3.08 & 0.78 & -0.14 & 0.07 & 1 & 5 \\
\hline I43 & 240 & 0 & 3.99 & 0.66 & -0.72 & 1.51 & 2 & 5 \\
\hline I44 & 240 & 0 & 4.04 & 0.60 & -0.37 & 1.12 & 2 & 5 \\
\hline I45 & 239 & $1(0.4 \%)$ & 3.85 & 0.68 & -0.52 & 0.64 & 2 & 5 \\
\hline I46 & 240 & 0 & 3.97 & 0.75 & -0.77 & 1.17 & 1 & 5 \\
\hline I47 & 240 & 0 & 3.43 & 0.84 & -0.25 & -0.24 & 1 & 5 \\
\hline I48 & 239 & $1(0.4 \%)$ & 3.51 & 0.83 & -0.38 & -0.04 & 1 & 5 \\
\hline I49 & 239 & $1(0.4 \%)$ & 3.48 & 0.81 & -0.42 & -0.05 & 1 & 5 \\
\hline $\mathrm{I} 50$ & 239 & $1(0.4 \%)$ & 3.59 & 0.86 & -0.28 & -0.53 & 2 & 5 \\
\hline I51 & 239 & $1(0.4 \%)$ & 3.99 & 0.79 & -0.61 & 0.20 & 2 & 5 \\
\hline
\end{tabular}


[1] I. Halloun, Views about science and physics achievement: The VASS story, AIP Conf. Proc. 399, 605 (1997).

[2] E. F. Redish, J. M. Saul, and R. N. Steinberg, Student expectations in introductory physics, Am. J. Phys. 66, 212 (1998).

[3] W. K. Adams, K. K. Perkins, N. S. Podolefsky, M. Dubson, N. D. Finkelstein, and C. E. Wieman, New instrument for measuring student beliefs about physics and learning physics: The Colorado Learning Attitudes about Science Survey, Phys. Rev. ST Phys. Educ. Res. 2, 010101 (2006).

[4] R. S. Barthelemy and A. V. Knaub, Gendered motivations and aspirations of university physics students in Finland, Phys. Rev. Phys. Educ. Res. 16, 010133 (2020).

[5] K. A. Douglas, M. S. Yale, D. E. Bennett, M. P. Haugan, and L. A. Bryan, Evaluation of Colorado Learning Attitudes about Science Survey, Phys. Rev. ST Phys. Educ. Res. 10, 020128 (2014).

[6] I. Kontro and D. Buschhüter, Validity of Colorado Learning Attitudes about Science Survey for a high-achieving, finnish population, Phys. Rev. Phys. Educ. Res. 16, 020104 (2020).

[7] A. Cavallo, W. Potter, and M. Rozman, Gender differences in learning constructs, shifts in learning constructs, and their relationship to course achievement in a structured inquiry, yearlong college physics course for life science majors, School Sci. Math. 104, 288 (2004).

[8] C. Lindstrøm and M. D. Sharma, Self-efficacy of first year university physics students: Do gender and prior formal instruction in physics matter?, Int. J. Innov. Sci. Math. Educ. 19, 1 (2011), https://openjournals.library.sydney.edu .au/index.php/CAL/article/download/4770/5767.

[9] H. Fencl and K. Scheel, Engaging students: An examination of the effects of teaching strategies on self-efficacy and course climate in a nonmajors physics course, J. Coll. Sci. Teach. 35, 20 (2005).

[10] J. M. Bailey, D. Lombardi, J. R. Cordova, and G. M. Sinatra, Meeting students halfway: Increasing self-efficacy and promoting knowledge change in astronomy, Phys. Rev. ST Phys. Educ. Res. 13, 020140 (2017).

[11] J. M. Nissen and J. T. Shemwell, Gender, experience, and self-efficacy in introductory physics, Phys. Rev. Phys. Educ. Res. 12, 020105 (2016).

[12] R. Dou, E. Brewe, J. P. Zwolak, G. Potvin, E. A. Williams, and L. H. Kramer, Beyond performance metrics: Examining a decrease in students' physics self-efficacy through a social networks lens, Phys. Rev. Phys. Educ. Res. 12, 020124 (2016).

[13] V. Sawtelle, E. Brewe, and L. Kramer, Exploring the relationship between self-efficacy and retention in introductory physics, J. Res. Sci. Teach. 49, 1096 (2012).

[14] Z. Y. Kalender, E. Marshman, C. D. Schunn, T. J. NokesMalach, and C. Singh, Damage caused by women's lower self-efficacy on physics learning, Phys. Rev. Phys. Educ. Res. 16, 010118 (2020).

[15] E. Marshman, Z. Y. Kalender, T. Nokes-Malach, C. Schunn, and C. Singh, Female students with A's have similar self-efficacy as male students with C's in introductory courses: A cause for alarm?, Phys. Rev. Phys. Educ. Res. 14, 020123 (2018).
[16] R. Dou, E. Brewe, G. Potvin, J. P. Zwolak, and Z. Hazari, Understanding the development of interest and self-efficacy in active-learning undergraduate physics courses, Int. J. Sci. Educ. 40, 1587 (2018).

[17] S. L. Britner, Motivation in high school science students: A comparison of gender differences in life, physical, and earth science classes, J. Res. Sci. Teach. 45, 955 (2008).

[18] E. Marshman, Z. Y. Kalender, C. Schunn, T. NokesMalach, and C. Singh, A longitudinal analysis of students' motivational characteristics in introductory physics courses: Gender differences, Can. J. Phys. 96, 391 (2018).

[19] Z. Y. Kalender, E. Marshman, C. Schunn, T. NokesMalach, and C. Singh, Gendered patterns in the construction of physics identity from motivational factors, Phys. Rev. Phys. Educ. Res. 15, 020119 (2019).

[20] A. Gungor, A. Eryılmaz, and T. Fakıoglu, The relationship of freshmen's physics achievement and their related affective characteristics. J. Res. Sci. Teach. 44, 1036 (2007).

[21] B. D. Geller, J. Gouvea, B. W. Dreyfus, V. Sawtelle, C. Turpen, and E. F. Redish, Bridging the gaps: How students seek disciplinary coherence in introductory physics for life science, Phys. Rev. Phys. Educ. Res. 15, 020142 (2019).

[22] A. Abak, Modeling the relationship between university students' selected affective characteristics and their physics achievement, unpublished Master's thesis, Middle East Technical University, Turkey, 2003.

[23] O. D. Tekiroglu, Explaining The relationship between high school student's selected affective characteristics and their physics achievement, unpublished Master's thesis, Middle East Technical University, Turkey, 2005.

[24] U. Islim, Öğrencilerin duyuşsal karakteristiklerinin fizik dersi başarısına etkisi, unpublished Master's thesis, Selcuk University, Turkey, 2006.

[25] A. Gungor and A. Eryilmaz, Gender differences in freshmen's physics related affective characteristics, in Proceedings of the GIREP Conference 995 (University of Amsterdam, Amsterdam, 2006).

[26] H. Pesman and O.F. Ozdemir, Approach-method interaction: The role of teaching method on the effect of context-based approach in physics instruction, Int. J. Sci. Educ. 34, 2127 (2012).

[27] H. Pesman, Interaction of student motivation with contextual approach and 5e learning cycle in physics, Universitepark Bulten 4, 16 (2015).

[28] S. Ergin and M. Sari, The effect of 4MAT instruction method in physics education on students' selected affective characteristics, Hacettepe Uni. J. Educ. 31, 212 (2016), http://www.efdergi.hacettepe.edu.tr/yonetim/ icerik/makaleler/1979-published.pdf.

[29] D. Gurcay and H. O. Ferah, The effects of students' physics self-efficacy and achievement motivation on their learning approaches, Australian Acad. Business Econ. Rev. 2, 303 (2017), http://aaber.com.au/index.php/AABER/ article/download/35/35.

[30] S. Sunar, The effect of context-based instruction integrated with learning cycle model on students' achievement and retention related to states of matter subject, unpublished Ph.D. thesis, Middle East Technical University, Turkey, 2013. 
[31] S. J. Priniski, C. A Hecht, and J. M. Harackiewicz, Making learning personally meaningful: A new framework for relevance research, J. Exp. Educ. 86, 11 (2018).

[32] S. Hidi and K. A. Renninger, The four-phase model of interest development, Educ. Psychol. 41, 111 (2006).

[33] U. Schiefele, Interest, learning, and motivation, Educ. Psychol. 26, 299 (1991).

[34] S. Hidi, Interest and its contribution as a mental resource for learning, Rev. Educ. Res. 60, 549 (1990).

[35] K. A. Renninger, Individual interest and its implications for understanding intrinsic motivation, in Intrinsic and Extrinsic Motivation (Academic Press, New York, 2000), p. 373.

[36] A. Bandura, Social Foundations of Thought and Action: A Social Cognitive Theory (Prentice Hall, Englewood Cliffs, NJ, 1986).

[37] H. W. A. Marsh, Multidimensional, hierarchical model of self-concept: theoretical and empirical justification, Educ. Psychol. 2, 77 (1990).

[38] R. W. Lent, S. D. Brown, and P. A. Gore, Discriminant and predictive validity of academic self-concept, academic selfefficacy, and mathematics-specific self-efficacy, J. Counsel. Psychol. 44, 307 (1997).

[39] Collins COBUILD English Language Dictionary, edited by J. Sinclair (HarperCollins Publishers, London, 1993), p. 54.

[40] E. S. Elliott and C. S. Dweck, Achievement Motivation. Handbook of Child Psychology: Social and Personality Development (Wiley, New York, 1983), p. 643.

[41] Dictionary of Education, 3rd ed., edited by C. V. Good (McGraw-Hill, New York, 1973).

[42] J. S. Oliver and R. D. Simpson, Influences of attitude toward science, achievement motivation, and science self-concept on achievement in science: a longitudinal study, Sci. Educ. 72, 143 (1988).

[43] A. Edwards, Techniques of Attitude Scale Construction (Appleton-Century-Crofts, New York, 1957).

[44] E. Taslidere, Factors affecting 12th-grade students' physics achievement, Psychol. in the Schools 57, 1385 (2020).

[45] A. A. Gungor, Teaching practices enhancing students' affective characteristics related to physics, unpublished Ph.D. thesis, Middle East Technical University, Turkey, 2010.

[46] E. Taslidere and A. Eryilmaz, Basit elektrik devreleri konusuna yönelik tutum ölçeği geliştirilmesi ve öğrencilerin tutumlarının değerlendirilmesi, J. Turkish Sci. Educ. 9, 31 (2012), http://www.tused.org/index.php/tused/article/ view/419/357.

[47] E. Gulbas, An investigation of the relationship among students' understandings of heat, temperature and internal energy concepts, learning orientations and some affective characteristics, unpublished Master's thesis, Hacettepe University, Turkey, 2013.

[48] M. S. Bulbul, The effect of enriched course materials about motion on ninth grade sighted and totally blind students' achievement, motivation, attitude, perception of learning environment and interaction in inclusive classes, unpublished Ph.D. thesis, Middle East Technical University, Turkey, 2014.

[49] M. D. Miller, R. L. Linn, and N. E. Gronlund, Measurement and Assessment in Teaching, 10th ed. (Pearson Education, Upper Saddle River, New Jersey, 2009).
[50] M. T. Kane, Validating the interpretations and uses of test scores, J. Educ. Measure. 50, 1 (2013).

[51] L. Crocker and J. Algina, Introduction to Classic and Modern Test Theory (Cengage Learning, Ohio, 2008).

[52] A. Nair and V. Sawtelle, Operationalizing relevance in physics education: Using a systems view to expand our conception of making physics relevant, Phys. Rev. Phys. Educ. Res. 15, 020121 (2019).

[53] The Flemish Ministry of Education (2020); retrieved from https://onderwijs.vlaanderen.be/nl/hoger-onderwijsin-cijfers\#2020-2021.

[54] H. W. Marsh and K. T. Hau, J.R Balla, and D. Grayson, Is more ever too much? The number of indicators per factor in confirmatory factor analysis, Multivariate Behav. Res. 33, 181 (1998).

[55] W. Herzog and A. Boomsma, Small-Sample Robust Estimators of Noncentrality-Based and Incremental Model Fit, Struct. Eq. Modeling 16, 1 (2009).

[56] C. G. Forero, A. Maydeu-Olivares, and D. Gallardo-Pujol, Factor analysis with ordinal indicators: A Monte Carlo study comparing DWLS and ULS estimation, Struct. Eq. Modeling 16, 625 (2009).

[57] Y. Rosseel, lavaan: An R Package for Structural Equation Modeling, J. Stat. Softw. 48, 1 (2012), http://www.jstatsoft .org/v48/i02/.

[58] C. H. Li, The performance of MLR, USLMV, and WLSMV estimation in structural regression models with ordinal variables, unpublished Ph.D. thesis, Michigan State University, Michigan, 2014.

[59] See Supplemental Material at http://link.aps.org/ supplemental/10.1103/PhysRevPhysEducRes.17.010132 for the R-code of the CFA of the Model 4 (without item 23) with ULSM estimation method used in R-lavaan package to conduct the analysis.

[60] A. Boomsma, Reporting analyses of covariance structures, Struct. Eq. Modeling 7, 461 (2000).

[61] T. A. Brown, Confirmatory Factor Analysis for Applied Research (Guilford Press, New York, 2015).

[62] L. Hu and P. M. Bentler, Cutoff criteria for fit indexes in covariance structure analysis: Conventional criteria versus new alternatives, Struct. Eq. Modeling 6, 1 (1999).

[63] B. M. Byrne, Structural Equation Modeling with AMOS: Basic Concepts, Applications, and Programming (Routledge, New York, 2013).

[64] H. W. Marsh, J. Guo, T. Dicke, P. D. Parker, and R. G Craven, Confirmatory factor analysis (CFA), exploratory structural equation modeling (ESEM), and set-ESEM: optimal balance between goodness of fit and parsimony, Multivariate Behav. Res. 55, 102 (2020).

[65] D. Hooper, J. Coughlan, and M. R. Mullen, Structural equation modelling: Guidelines for determining model fit, Electronic J. Business Res. Methods 6, 53 (2008), https:// academic-publishing.org/index.php/ejbrm/article/view/ 1224/1187.

[66] R. E. Schumacker and R. G. Lomax, A Beginner's Guide to Structural Equation Modeling (Third) (Routledge, New York, 2010).

[67] C. Y. Yu, Evaluating cutoff criteria of model fit indices for latent variable models with binary and continuous 
outcomes, unpublished Ph.D. thesis, University of California, Los Angeles, California, 2002.

[68] Y. Xia and Y. Yang, RMSEA, CFI, and TLI in structural equation modeling with ordered categorical data: The story they tell depends on the estimation methods, Behav. Res. Methods 51, 409 (2019).

[69] T. Raykov, Estimation of composite reliability for congeneric measures, Appl. Psychol. Meas. 21, 173 (1997).
[70] S. R. Colwell, The composite reliability calculator [Technical report]. URL http://www.thestatisticalmind.com/ calculators/comprel/composite_reliability.htm (2016).

[71] D. Woitkowski and N. L. Wurmbach, Assessing German professors' views of nature of science, Phys. Rev. Phys. Educ. Res. 15, 010108 (2019).

[72] J. Osborne, S. Simon, and S. Collins, Attitudes towards science: A review of the literature and its implications, Int. J. Sci. Educ. 25, 1049 (2003). 